\title{
ESCRITURA DE FICCIÓN Y ATESTACIÓN DEL SÍ
}

\section{Fiction writing and Self-attestation}

\section{Roque Diómedes Santos Cueto}

Profesor Investigador de la Universidad Autónoma de Santo Domingo (UASD), Santo Domingo, República Dominicana

ORCID: 0000-0001-6595-1892, Correo-e: rsantos30@uasd.edu.do,santos_roque@hotmail.com

\section{Recibido: 14/03/2020 • Aprobado: 20/4/2020}

Cómo citar: Santos Cueto, R. D. (2020). Escritura de ficción y atestación del sí. Ciencia y Sociedad, 45(2), 51-62. Doi: https://doi. org/10.22206/cys.2020.v45i2.pp51-62

\section{Resumen}

La escritura de ficción es un recurso reflexivo para la atestación del sí; esta última es un saberse en el camino del ser verdadero llamado a la actuación ética responsable. A partir de una precomprensión del mundo de la acción humana, mediado por el esquematismo narrativo desplegado en la construcción de una trama, el relato de una vida se vuelve inteligible no solo en términos de memoria o reconstrucción histórica, también como manera de ser o de invención de mundos posibles lo que permite una serie de variaciones imaginativas del ego que constituyen un acceso privilegiado al sí desde el quiasmo entre el análisis y la reflexión. En el siguiente trabajo se analiza la hermenéutica reflexiva de Paul Ricoeur para constatar cómo el papel heurístico de la escritura de relatos de ficción, como producto de lo imaginario, permite la configuración de un sí mismo por mediación del lenguaje. A pesar del énfasis que el autor francés coloca en la actividad lectora, dado su rol mediador entre el mundo proyectado por el texto y la vida, en su hermenéutica del sí y en su teoría narrativa encontramos la posibilidad de extender algunos conceptos clave de esta hermenéutica a la actividad escrituraria como mediación entre el mundo de la acción y el mundo del texto. Lo que permite analizar el papel de lo imaginario en la configuración del sí a través de la escritura de relatos de ficción.

Palabras clave: narración; relato; identidad; imaginación creativa; lenguaje.

\begin{abstract}
Fiction writing is a reflective resource for self-attestation; The self-attestation is knowing oneself on the path of being truly called to responsible ethical action. Starting from a pre-understanding of the world of human action, mediated by the narrative schematism displayed in the construction of a plot, the story of a life becomes intelligible not only in terms of memory or historical reconstruction, but also as a way of being or of invention of possible worlds which allows a series of imaginative variations of the ego that constitute a privileged access to the self from the chiasm between analysis and reflection. In the following work, the Paul Ricoeur's reflexive hermeneutics is analyzed to verify how the heuristic role of writing fiction stories, as a product of the imaginary, allows the configuration of a self through the mediation of language. Despite the emphasis that the French author places on reading activity, given his mediating role between the world projected by the text and life, in his hermeneutic of the self and in his narrative theory we find the possibility of extending some key concepts of this hermeneutic writing activity as a mediation between the world of action and the world of text. This allows us to analyze the role of the imaginary in the configuration of the self through the writing of fictional stories.
\end{abstract}

Keywords: Narration; story, identity, creative imagination, language. 


\section{Introducción}

Paul Ricoeur es un hermeneuta que da qué pensar. Su obra es vasta y compleja. En sus inicios el autor se inscribe en una hermenéutica reflexiva surgida desde Descartes y Kant, pero bajo la línea inspirada por Jean Nabert y otros; autores que incidirán en sus años de formación intelectual y en su posterior preocupación por la cuestión del símbolo y la obra de Freud (Ricoeur, 1997, p. 32). Sus primeras publicaciones conforman un proyecto de antropología filosófica dividido en una eidética, una empírica y una poética (Ricoeur, 1997, p. 27). Este proyecto se realizó en sus dos primeras partes. La tercera se vio frustrada (Moratalla, 1991, p. 6), pero generó una hermenéutica reflexiva enfocada en el problema de la creatividad en el lenguaje y el acceso indirecto a la conciencia de sí.

Esta hermenéutica inicia en 1969 con la publicación de El Conflicto de las Interpretaciones y tiene su punto final en 1990 con Sí mismo como otro. En todo este periodo, la creatividad reglada y el acceso indirecto al sí mismo permearon de forma implícita la preocupación ricoeuriana sobre el texto y la persona actuante y sufriente; creando notas claras de lo que luego denominará de antropología del hombre capaz, en conexión con su proyecto primero. Aunque la noción de "hombre capaz", como señala Eduardo Casarotti, "aparece en la filosofía de Ricoeur a mitad de la década de los noventa" (2012, p. 271) esta es una idea articulable de toda su obra, el mismo Ricoeur se ha encargado de manifestarlo y que, a mi juicio, es esbozada a partir de la teoría del texto, la teoría de la acción, la teoría narrativa y de la pequeña ética trabajada en Sí mismo como otro de 1990.

En mi opinión esta antropología del hombre actuante y sufriente tiene como sustrato la tesis hermenéutica del rodeo de la reflexión por el análisis, esto es, la convicción ricoeuriana de que solo llegamos a nosotros mismos (el acceso al cogito) por la mediación del lenguaje (la cultura, los textos, las obras); convicción que le viene por su elección de la vía larga en el acceso a sí en lo que llamó una "ontología militante y quebrada” (Ricoeur, 2003, p. 26).

La hermenéutica reflexiva ricoeuriana entra en escena no ya como una disciplina que busca unas reglas para la interpretación de la vida que se objetiva en las obras culturales o bien como una disciplina preocupada por la sola cuestión de la comprensión de los textos (Schleiermacher-Dilthey), sino que, en tanto que condición misma y posibilidad histórica de ser en el mundo, es un modo de existir que se atestigua en la acción y el decir. Estos últimos como caminos fragmentarios de expresión y concretización de la persona.

Los textos, en su sentido amplio, pasan a hacer mediaciones para la interpretación del sí. Esto es, me reconozco en el conjunto de obras sedimentadas en la cultura y que me suelen ser significativas. Este mundo textual es posibilidad de conexión entre el lenguaje y la vida (Ricoeur, 1999b, p. 57) y de interpretación del sí por vía del análisis y la reflexión lo que muestra un diálogo entre la cultura y el sujeto.

La primera definición de hermenéutica en Ricoeur está bajo este diálogo entre la cultura (en sus símbolos y mitos) y el sujeto que no solo interpreta el doble sentido de las expresiones culturales simbólicas y míticas, sino a sí mismo por mediación de los textos. La mediación de los textos coloca la actividad lectora en el centro de la reflexión hermenéutica ricoeuriana. En otras palabras, su hermenéutica fenomenológica se centra en la lectura, en el desciframiento de la "cosa" expuesta o referida por el texto, el "mundo del texto". Ello trae en consecuencia pocas referencias a la actividad de escritura, lo que imposibilita situar en su justa medida el papel heurístico de la narrativa de ficción en la configuración del sí.

La opción del autor de centralizar la hermenéutica del texto en la actividad lectora, en detrimento de la escritura, nos ha llevado a explorar un camino 
posible de traslado de los conceptos ricoeurianos hacia el acto de escritura, tomando como paradigma los relatos de ficción. Ello con el objetivo de comprender el papel de lo imaginario (en cuanto producto de la imaginación creadora) en la constitución subjetiva de la identidad personal a través de una actividad escrituraria (Certeau, 1996) particular: el relato de ficción.

En esta travesía nos servirá como norte, primero, el concepto de atestación de sí a partir de los esbozos realizados en Sí mismo como otro; segundo, lo que concierne a la teoría narrativa y la teoría de la acción en algunos textos claves del periodo comprendido entre 1969 y 1990. Para justificar nuestra travesía sitúo brevemente la problemática de la escritura y la lectura en el origen y la tarea de la hermenéutica según lo planteado por el autor francés.

\section{La hermenéutica y la escritura: la problemática}

La reflexión sobre la hermenéutica que realiza Ricoeur posee una idea rectora: la restricción de la interpretación a una teoría de las operaciones de comprensión y explicación de textos o de obras culturales cuyo procedimiento de producción es similar a la fijación por la escritura (Ricoeur, 2002, p. 71). Esta idea se limita a retomar el resurgimiento de la hermenéutica a partir de la fusión entre la exégesis bíblica, la filología clásica y la jurisprudencia realizada por Schleiermacher (Ricoeur, 2002, p. 29).

Con esta limitación se deja de lado toda una discusión genealógica sobre los tres sentidos del concepto hermeneuien (Palmer, 2002, pp. 32-47). Primero, como modo de "transferir mensajes" (Ferraris, 2005, p. 13); segundo, como un "explicar" en el sentido de dar cuenta del contenido de algo y, tercero, como "traducir" para otros el contenido del mensaje.

En los tres sentidos del vocablo griego se descubre un doble proceso que es el que afectará, para Jean
Grondin (2008, p. 22), el sentido actual del vocablo hermenéutica y que, a partir de Ferrari (2005) y Palmer (2002), funcionan como una especie de núcleo integrador del vocablo en su acepción actual. Hermeneuien significaba entonces transmisión de mensajes (núcleo integrador) y para ello será necesario no solo un sentido que transmitir; sino realizar una operación interna de producción-comprensión (del sentido del mensaje) y traducción (del lenguaje de los dioses al lenguaje humano) del sentido producido-comprendido. El núcleo integrador (el sentido del mensaje) vehiculaba un doble proceso desde el interior al exterior $\mathrm{y}$ viceversa:

Hoy día solo hablamos de interpretación para caracterizar el segundo proceso, que asciende del discurso al pensamiento que lo sostiene, pero los griegos pensaban ya la elocución como un proceso "hermenéutico" de mediación de significados, que designa entonces la expresión o la traducción del pensamiento en palabras. (Grondin, 2008, p. 22)

Para Maurice Ferraris, la época helenística será el contexto adecuado para el surgimiento de la hermenéutica a partir del distanciamiento temporal del lector (2005, p. 15) respecto a los textos canónicos que formaron la cultura griega. Junto a esta focalización de la hermenéutica en la labor de interpretación de los textos canónicos de la cultura, se da la especialización de la Retórica y de la Poética, centradas ambas en los procesos de producción y no de interpretación.

En la cultura griega la hermenéutica no es un problema propiamente filosófico y lo que posteriormente se considerará como las tareas propias a la hermenéutica no eran restringidas a este saber, sino que otros saberes rińeron y ganaron la apuesta en la adjudicación de las labores interpretativas y productivas de los textos. Por ejemplo, la dialéctica platónica predominó en cuanto camino heurístico 
de acceso a la verdad. La Retórica y la Poética trabajaron por su cuenta lo relativo a la producción a través del lenguaje. En todo caso, la hermenéutica se restringió a la interpretación de los textos sagrados y dejó de ser una problemática propiamente filosófica hasta Schleiermacher cuya tarea fundadora es, a juicio de Ricoeur, desregionalizar la hermenéutica en una hermenéutica general que tratará las reglas universales para la correcta interpretación de los textos, fuesen sagrados o no; al respecto nos dice: "La hermenéutica surgió a partir de este esfuerzo por elevar la exégesis y la filología al rango de una Kunstlehre, es decir, de una tecnología que no se limita a una simple colección de operaciones desconectadas." (Ricoeur, 2002, pp. 73-74)

En este resurgimiento de la hermenéutica se mantiene la desconexión con el proceso elocutivo, con la producción del discurso, ello a pesar de que el "programa de Schleiermacher llevaba la doble marca romántica y crítica” (Ricoeur, 2002, p. 74). La hermenéutica romántica tendrá como propósito no solo centrar la tarea de la hermenéutica en la lectura, sino dar las bases epistemológicas para la incorporación del quehacer hermenéutico al rango de los problemas filosóficos. En consecuencia, la desregionalización de la hermenéutica se convierte en un énfasis epistemológico al pretender darle estatuto científico-social a la labor interpretativa.

En este periodo de la hermenéutica, el énfasis estará en la empatía entre la subjetividad del lector y el autor por mediación de la obra. El presupuesto que sustentará esta "empatía" entre ambas consciencias es, primero, el pacto entre hermenéutica y conocimiento histórico o, si se quiere, comprensión histórica y, segundo, la vida se objetiva en las obras culturales. De este modo, en la obra misma está en juego la conciencia objetivada de una vida ya realizada.

La conexión con los textos que mantuvo la hermenéutica romántica es perdida en la hermenéutica existencial de Martín Heidegger. Para este autor, la interpretación no es solo un modo de comprensión de textos, sino un modo de ser históricamente situado. Así la condición temporal del ser es el rasgo nuclear para el desarrollo de toda hermenéutica existencial. Ya la interpretación del texto, que en la hermenéutica romántica estaba en función del quién objetivado en la obra, se traslada plenamente, en la hermenéutica heideggeriana, al sentido de la existencia en el marco de la temporalidad. Aquí es cuando "el comprender no se dirige pues a la captación de un hecho, sino a la aprehensión de una posibilidad de ser" (Ricoeur, 2002, p. 86) que está históricamente condicionada. A pesar de que la "estructura de anticipación" de la experiencia humana está dada por este marco temporal, en el que la vida se ha objetivado reflexivamente y se me da en su marcado carácter lingüístico, sígnico; la tarea de la hermenéutica seguirá restringida a la comprensión y no a la producción.

Cuando Ricoeur nos dice que da "por sentado que el sentido primordial del término "hermenéutica" se refiere a las reglas requeridas para la interpretación de los documentos escritos de nuestra cultura..." (2002, p. 169) no está partiendo de su primera definición de hermenéutica, en la que se limita a una interpretación de las expresiones de doble sentido como juego en la que se da la equivocidad del ser (Ricoeur, 2003, p. 64), sino de un desplazamiento de la cuestión hermenéutica del símbolo al texto (Calvo Martínez, 1991, p. 118) en la que se aborda propiamente la cuestión de la interpretación de los textos como un procedimiento dialéctico entre los procesos de comprender y explicar (Ricoeur, 1995, p. 83).

Pasar de una interpretación simbólica a una interpretación textual es sostener el carácter restrictivo que apuntábamos más arriba para la labor hermenéutica, ya que la "esfera de la interpretación" se reduce a la "escritura" y es sostener, al mismo tiempo, la labor de distanciamiento que ocurre por la fijación de la palabra escrita. En efecto, la independencia semántica que adquiere un texto fijado por la escri- 
tura, respecto a su contexto de producción, abre espacio para el conflicto de interpretación del discurso que ha "devenido" texto.

En Ricoeur, la tarea de la hermenéutica está posibilitada por esta labor de distanciamiento o distanciación que sucede en el discurso cuando es fijado por la escritura. La triple autonomía semántica (intención del hablante, recepción del público primitivo y contexto de producción del discurso) le obliga a situar la hermenéutica de cara a la apropiación de la "cosa del texto". El mundo del texto dado por la obra es lo que se ofrece para la interpretación. Así se separa la obra del acontecimiento discursivo que le da origen. De este modo, la dialéctica entre el acontecimiento discursivo y el sentido producido prepara el terreno para la apropiación del mundo del texto a través del acto de lectura. Por ello es por lo que Ricoeur plantea que "la lectura es este acto concreto en el cual se consuma el destino del texto. En el corazón mismo de la lectura se oponen y se concilian indefinidamente la explicación y la interpretación”. (Ricoeur, 2002, p. 147).

Utilizando el lenguaje fregeano (Frege, 1998) podemos afirmar que el sentido es dado por el texto para ser interpretado por un lector que, en una última instancia, es quien trae el texto a la vida. El lector es quien refiere y se apropia de la cosa del texto o el mundo que el texto proyecta en tanto que discurso (Ricoeur, 1987b, p. 18), ya que la referencia ostensiva a la realidad está suspendida, como también ocurre en el enunciado metafórico (Ricoeur, 2001, p. 298). De esta forma, la lectura no solo es la operación mediadora entre el texto y la vida; también es la operación central para la hermenéutica del texto, desplazando a la escritura.

El problema es que la mediación lingüística del texto obliga a "buscar en el texto mismo, por una parte, la dinámica interna que rige la estructuración de la obra y, por otra, la capacidad de la obra para proyectarse fuera de sí misma y engendrar un mundo que sería verdaderamente la cosa del texto". (Ricoeur, 2002, p. 33)
Esta decisión metodológica de centrarse en el texto y en el lector es problemática porque el propio autor nos solo señala que:

...incumbe a la hermenéutica reconstruir el conjunto de las operaciones por las que una obra se levanta sobre el fondo opaco del vivir, del obrar y del sufrir, para ser dada por el autor a un lector que la recibe y así cambia su obrar (Ricoeur, 1987a, p. 118)

Con ello extiende los alcances de una hermenéutica del texto a una hermenéutica del sí mismo donde el texto funge como paradigma de interpretación del mundo de la acción humana y de las Ciencias Sociales. (Ricoeur, 2002, p. 169-195). Tenemos la sospecha de que en Ricoeur no solo ocurre un desplazamiento del símbolo al texto (Calvo Martínez, 1991), sino que va del texto a la acción en una especie de continuidad problematizadora para mostrar sus dos convicciones hermenéuticas: el rodeo de la reflexión por el análisis y la mediación del lenguaje en la configuración del sí. En este paso de una hermenéutica del texto, por mediación de una teoría de la acción y una teoría narrativa, a una hermenéutica del sí mismo que puede ser catalogada como una hermenéutica reflexiva o una hermenéutica subjetiva, se continúa en una teoría de la interpretación centrada en la lectura, dejando de explorar los horizontes abiertos por la teoría de la acción y la teoría del discurso narrativo para la comprensión del sí a través de la escritura.

Nuestro propósito, desde la hermenéutica del sí esbozada en Sí mismo como otro, es extender algunos conceptos ricoeurianos centrados en la lectura hacia el acto de escritura tomando como paradigma el relato de ficción literaria. El pretexto para bosquejar brevemente esta empresa será establecer el papel de lo imaginario en la configuración del sí reflexivo, que es muy distinto al "yo". Nos mueve la tesis de que el acto de escritura, en cuanto apropiación de sentido del mundo de la acción a través del lenguaje y en 
cuanto figuración imaginativa de una posibilidad de actuación en el campo práctico, es posibilidad de atestación del sí por vía del análisis y la reflexión. De otra forma, la producción de relatos de ficción, como actividad escrituraria en la que se reflexiona sobre una vida o se proyecta algún aspecto del actuar humano, constituye una "apropiación no disgregadora de la contingencia” (Nájera, 2006, p. 79) y allí surte efecto el acto identitario del sujeto que reflexiona sobre sí mismo como un "otro", el sí reflexivo, bajo el prisma del esquematismo narrativo.

\section{La interpretación del sí y la narratividad}

La hermenéutica de Paul Ricoeur en Sí mismo como otro puede clasificarse como una ontología articulada de modo indirecto a través de los conceptos de identidad narrativa y de atestación del sí bajo la llamada ética. Esta ontología es mediada por el análisis y la reflexión de las capacidades de actuar y decir en el marco de la temporalidad.

Para nuestro autor, la persona se expresa en diversos niveles de discursos regulados por la pregunta ¿quién?: quién habla, quién actúa, quién narra, quién es el sujeto responsable factible de ser imputado moralmente. Por tanto, buscar la identidad de este sujeto capaz de actuar y de padecer es posible vía las mediaciones en las que se dice, actúa, se narra y se orienta moralmente en la vida; ello en vista de que estas mediaciones son las objetivaciones en las que se expresa en cuanto persona, como un "yo puedo", y en vista a que la subjetividad solo puede ser una identidad narrativa a la que se llega por vía indirecta, como un "otro" reflexionado. (Ricoeur, 2006, p. 16)

En estas mediaciones se parte del concepto persona para llegar a la reflexividad del sí a través de los encadenamientos de las tres dialécticas que constituyen la hermenéutica del sí y los ámbitos de reflexividad permitidos por los procesos de individuación, identificación e imputación moral. Solo al final del proceso la interpretación del sí pasa del nivel epistémico de la atestación, en cuanto camino aléthico de confianza, al nivel ontológico requerido, en donde la hermenéutica del sí es una ontología mediada por el nivel pragmático de la vida práctica. O bien: la atestación del sí pasa por niveles cada vez más complejos de compromiso ontológico en que la persona se reconoce a sí misma y actúa como sujeto ético desde la unidad de una vida examinada.

Como vemos, la hermenéutica reflexiva de Ricoeur parte del ámbito del lenguaje hasta llegar al de la vida práctica, teniendo como mediación en el proceso la narratividad del agente que dice su hacer desde su historicidad. Las imbricaciones y encadenamientos de estos ámbitos, dialécticas, niveles y procesos reflexivos son la puerta de entrada a la teoría narrativa de la identidad personal en correlación con la atestación del sí en su nivel ontológico, es decir, como certeza de que se está en el camino del ser verdadero, aunque siempre bajo la mirada de la sospecha.

En el quién habla, que corresponde al nivel lingüístico de una fenomenología del sí mismo, el sujeto que se desvela no es un sujeto responsable de sí, sino apenas identificable como capaz de enunciación por las referencias identificantes del discurso. Este sujeto lingüístico comunica el sentido de una experiencia en un acontecimiento discursivo desde el cual puede autodesignarse y autoidentificarse, pero no es un sí reflexivo responsable porque faltaría el nivel práctico del actuar humano. La atestación que se produce en este nivel está en el entrecruzamiento entre el análisis y la reflexión, pero solo a nivel de reconocimiento del sí por sus atributos identificantes.

Pasando al nivel práctico, el de la acción humana, es cuando nos damos cuenta de que la estructura del mundo de la acción posee una carga temporal que solo es aprehensible de forma narrativa. Aquí el tiempo cósmico se hace tiempo humano y la narración es "significativa en la medida en que describa 
los rasgos de la experiencia temporal" (Ricoeur, 1987a, p. 41). En este ámbito práctico se formula la identidad del agente que se expresa y descubre siendo el mismo a pesar de los cambios en el tiempo. Esto es, en la unidad de una vida se decanta la identidad personal como un constructo imaginado, como una "figura" del sí que se construye a partir del análisis del mundo de la acción humana y como proyección del yo puedo hacia ese mundo de la acción; en ambas formas, la acción es imputable ética y moralmente a su agente y descriptible en sus motivaciones y en sus fines. Así el nivel práctico se incorpora al nivel ético del sí reflexivo mediante la atestación del sí que se ha iniciado por el análisis y la reflexividad del mundo de la acción.

En el tránsito de estos niveles, la hermenéutica del sí se ha expresado en sus dialécticas constitutivas, a saber: la dialéctica entre el análisis y la reflexión, entre la ipseidad y la mismidad y entre la ipseidad y la alteridad (Ricoeur, 1996a, p. 328). La integración de estas dialécticas en los niveles de discursos permite no solo identificar al sujeto que es capaz de actuar y sufrir, sino al sujeto que se descubre a sí mismo como responsable (de sí y frente al otro) desde una vida éticamente intencionada por vía del esquematismo narrativo que aplica sobre la acción humana; a la que no solo redescribe heurísticamente, sino que la proyecta como posibilidad de ser.

Ahora bien, el carácter semiológico de la acción (Ricoeur, 1988) es lo que permite explicarla, comprenderla como un texto (Ricoeur, 2002, p. 192) y retraerla a su agente fuente. El sujeto responsable es el que se reconoce como agente de la acción intencionada que interviene en el mundo. En este sentido, es necesario que los niveles anteriores de reflexividad de la hermenéutica del sí, el lingüístico y el práctico, se incorporen al tercer nivel, el ético, porque es donde podemos no solo atribuir determinada acción a su agente, sino hacer juicios deliberativos de esta acción en el mundo. El agente responsable es el factible de imputación moral
(Ricoeur, 1996a, p. 323) y no solo de adscripción de ciertos rasgos constitutivos.

La responsabilidad y la imputación moral de la persona se estructuran en lo que Ricoeur llama respeto de sí y estima de sí. Tanto el respeto como la estima de sí muestran con mayor fuerza el problema de la atestación del sí que en los niveles anteriores, el lingüístico y el práctico, en donde apenas se esbozaba como reflexividad. La atestación del sí se juega ahora de forma tensional entre una fenomenología del "yo puedo" y una ontología hermenéutica que tiene como marco reflexivo la cuestión del cogito en una posición intermedia entre el cogito exaltado de Descartes y el cogito quebrado de Nietzsche (Ricoeur, 1996a, p. XXXVII).

Se trata de ser "atestiguado" como un sí reflexivo a través del uso responsable de mis capacidades y mi intervención en el mundo bajo el respeto de sí y la estima de sí. La norma moral que me antecede y me obliga al cuidado no tan solo de mí, también del otro, resulta ser el correlato subjetivo de la obligación moral, mientras que la intencionalidad de una vida buena deviene en el correlato subjetivo de la intencionalidad ética. Estima de sí y respeto de sí constituyen la atestación de sí en cuanto sujeto responsable y capaz de actuar y decir. Al respecto, nos dice Ricoeur en un texto publicado originalmente en alemán en 1989 lo siguiente:

Si la estima de sí constituye el correlato subjetivo de la evaluación ética de las acciones, el respeto constituye el correlato subjetivo de la obligación moral. Pero, mientras que la estima de sí podría solo implicar a mí, a mí solo, el respeto presenta en conjunto una estructura dialógica, paralelamente a la estructura conflictual de la interacción. Es necesario decir que cuando soy yo mismo que me estimo, yo me respeto en tanto que otro, en tanto que otros. Es el otro en mí que yo respeto. (Ricoeur, 2013, p. 324) 
Atestación del sí, repetimos, es saberse en el camino del ser verdadero, es reconocerse a sí mismo en la unidad de una vida bajo la dimensión ético-moral. Aquí es cuando el carácter narrativo de la temporalidad permite bosquejar los caminos de la atestación a través del rodeo del esquematismo narrativo. Este rodeo narrativo también concede una mejor clarificación de las dos dialécticas restantes en la estructura hermenéutica del sí: la dialéctica ipseidad-mismidad y la dialéctica ipseidad-alteridad. Ello porque la constitución temporal de la vida humana tiene como correlato una estructura narrativa que la hace inteligible y porque, como dice Ricoeur al final de Tiempo y Narración III: "El sí-mismo puede así decirse refigurado por la aplicación reflexiva de las configuraciones narrativas" (1996b, p. 998).

En este sentido, la identidad personal solo puede ser narrativa en la medida en que las variaciones imaginativas a las que el relato somete al ego reflejan los dos polos dialécticos de la identidad: la mismidad del carácter o identidad-ídem y el mantenimiento de sí o la identidad-ipse (Ricoeur, 1996a, p. 147) y ello es evidente en la construcción del discurso narrativo, en el desarrollo de la identidad del personaje, en ningún caso no comparable pura y simplemente a la identidad del autor del discurso.

La refiguración narrativa (mímesis III) de la cohesión de una vida (Ricoeur, 1996b, p. 998) abre un espacio de constitución o construcción de una "figura" de sí en la configuración de un relato (mímesis II) que parte de una prefiguración del mundo (mímesis I) de la acción humana (Ricoeur, 1987a, p. 118). Entonces las variaciones imaginativas, como una especie de esquematismo kantiano producto de la imaginación creativa o productora, no solo ocurre desde la actividad lectora, como una refiguración de la trama configurada por el relato como propone nuestro autor, sino que también ocurre en la actividad escrituraria reflexiva desde el mundo de la acción al mundo del texto por aplicación del esquematismo narrativo. Con otras palabras: hay esque- matismo narrativo en la prefiguración del relato que acontece en la actividad escrituraria y no solo en la refiguración del relato a través de la lectura.

Esto es importante porque, como bien dice Ricoeur, es en el ámbito de la intersección entre la teoría narrativa y la identidad personal en que "alcanza su pleno desarrollo la dialéctica concreta de la ipseidad y de la mismidad" (1996a, p. 107), ya que es la dialéctica central para el acceso mediado al cogito quebrado, el cual no es más que el sí reflexivo. Captar la esencia de la estructura narrativa de nuestra experiencia humana del tiempo, la narratividad, es adoptar el relato como réplica poética a la temporalidad por vía de la función narrativa explicitada en la construcción de una trama (mythos) que imita (mímesis) el mundo de la acción.

Sabemos que la trama constituye la puesta en escena de un relato que, bajo su dimensión configurativa y su dimensión episódica, articula la vivencia de la condición temporal. A partir de la trama del relato lo disperso del mundo de la acción humana adquiere unidad significativa en un todo estructurado; de modo que podemos hacerla más inteligible en términos de reflexividad y de atestación del sí. La trama es "el correlato de la inteligencia narrativa” (Ricoeur, 1987a, p. 27) y esta inteligibilidad no solo está en el acto de leer una historia y poder seguirla; también está en la escritura bajo el prisma del esquematismo narrativo (Mora, 2009, p. 709), lo que constituye una competencia necesaria para la configuración de la historia contada.

La inteligencia narrativa no está solo en el lector que se apropia del mundo proyectado por el texto y que comunica la obra con la vida, sino que la obra anteriormente ha partido de la vida y ha captado de ella su constitutiva estructura prenarrativa porque está referida al mundo de la acción. De este último es de donde sacamos los conceptos y las reglas que constituyen el esquematismo narrativo, que es la condición para la inteligibilidad del fragmentario 
mundo de los acontecimientos humanos y para la inteligibilidad de una vida examinada éticamente.

Es cierto que la vida biológica es dispersa, fragmentaria. Ahora bien, la vida humana es aquella vida reflexionada y examinada en términos de intencionalidad ética, lo que permite a un agente hacer consciencia de sí de cara al mundo, a los demás y a sí mismo. Esta triple relación de referencialidad, comunicabilidad y comprensión de sí es ejecutada por el acto configurante (la actividad escrituraria) antes que el acto reconfigurante (la actividad lectora). La obra literaria extrae de la vida lo que lleva al lenguaje. Evidentemente, en el acto poético se realizan una serie de opciones formales estéticas, cognoscitivas y éticas (Bajtín, 1999) que delatan el genio creador del autor, pero ello es imposible sin este marco común que llamamos mundo de la acción y que está sedimentado en la cultura.

La réplica poética a nuestra vivencia del tiempo y sus paradojas es posible hacerla desde el relato porque poseemos una inteligencia narrativa que nos permite captar como una totalidad significativa lo disperso del mundo de la acción. En este sentido, el acto configurante es síntesis de lo heterogéneo, es concordancia discordante posibilitada por la elaboración de la trama que surge de la imaginación creadora. El acto configurante del relato de ficción no es solo técnica o dominio formal del arte narrativa, es también captación sintética en donde prima la concordancia sobre lo discordante porque hemos captado estos esquemas de la cultura y lo aplicamos al conocimiento del mundo y de nosotros mismos. Aquí es cuando la imaginación realiza su actividad sintética por vía del esquematismo de la función narrativa y lo hace o bien con un valor mimético (de redescripción de la acción humana) o con un valor proyectivo en el que imaginativamente mido el alcance del "yo puedo" (Ricoeur, 2002, p. 206). En este sentido el esquematismo narrativo es un ejemplo eficaz de las variaciones imaginativas (Mora, 2009, p. 710) que permiten redescribir la realidad y proyectar las posibilidades del ser.
En términos de dialéctica entre mismidad del carácter e ipseidad o mantenimiento de sí en la palabra dada, el relato funge como mediación y garantía para la identidad narrativa puesto que el proceso de identificación y reconocimiento del sí como agente capaz de actuar y de decir se hace bajo esta estructura prenarrativa de la vida humana. La comprensión del sí, posibilitada por el acto poético configurante y su esquematismo narrativo, se hace por vía del rodeo del lenguaje y no como un acceso inmediato a sí mismo. En este acceso mediado la comprensión de sí incorpora los rasgos permanentes del sí mismo, el carácter o la mismidad, y la permanencia de sí a pesar de los cambios, la ipseidad. La identidad personal que posibilita el acto poético de construcción de una historia imaginada es ficticia, ciertamente, pero es "figura" del sí que, como toda experiencia de pensamiento, constituyen variaciones imaginativas del ego.

En el esquematismo narrativo está la posibilidad reflexiva de volver a sí como otro porque la labor de escritura es laboratorio para las experiencias de pensamiento ligadas al mundo de la acción humana. La trayectoria del personaje de la historia contada es un juego imaginativo con dimensiones heurísticas para la comprensión de sí, del mundo y de los demás. Según el propio Ricoeur (2006) "la ficción, principalmente la ficción narrativa, es una dimensión irreductible de la contemplación de sí mismo" (p. 20). El relato, bajo el esquematismo narrativo, no solo pone en orden nuestra experiencia temporal del mundo de la acción, sino que nos permite la comprensión del sí por la vía del análisis y la reflexividad.

\section{Conclusión}

Si la poética aborda las reglas de composición del texto es necesario que hablemos de poética de la ficción literaria, o simplemente ficción, para apuntar a las reglas de composición del discurso narrativo de ficción cuya pretensión de verdad no está sujeta a la verdad empírica, sino a la propia inteligibilidad 
del discurso (Ricoeur, 1999a, p. 84); esto es, a su modo de elaboración ya que es un producto del lenguaje desde la imaginación productora y enfocado en una representación verbal del mundo de la acción.

Desde el lenguaje fregeano de sentido y referencia extendido al discurso narrativo, el relato de ficción es aquel cuya referencia al mundo de la acción no es ostensiva (descriptiva) sino heurística porque "redescribe" desde la imaginación productora el "como si" del mundo de la acción. De esta forma, la mímesis no es mera copia de lo real al estilo Platón, sino una "representación" o "imitación" creativa a través del lenguaje del mundo de la acción mediante la elaboración de la trama (mythos). El sentido del relato de ficción está en ofrecer un mundo semánticamente autónomo (el mundo del texto) en el que se configuran las variaciones imaginativas del ego o de algún aspecto de lo real como un "mundo posible" o una posibilidad de ser.

La ficcionalidad que es presupuesta en la teoría de los mundos posibles ficcionales está dada por la estructura antropológica de la doble significación de Wolfgang Iser (Garrido Domínguez, 1997, pp. 43-65) o la estructura ontológica de la realidad de Thomas Pavel (Garrido Domínguez, 1997, pp. 171-180). Para ambos la ficcionalidad es una matriz generadora de significados a partir de un discurso representado. El carácter de "casi-cosas" de las representaciones textuales ficticias no declara una presencia metafísica de un mundo paralelo al nuestro, como lo hace la teoría de los mundos posibles de Saul Kripke (2005), sino como un universo semántico generador de experiencias de significados que pueden tomarse como posibilidades de reconstrucción de lo real o de sí mismo en cuanto posibilidad de ser; que es lo que, con Ricoeur, se ha llamado de variaciones imaginativas del ego a partir del esquematismo narrativo.

En todo caso, los mundos posibles ficcionales actúan como modelos de mundos autorreferenciales cuya conexión con lo real está suspendida y en tal virtud permiten el juego de figuraciones del mundo de la acción humana y permiten la proyección de una posibilidad de ser imaginada.

La fuerza heurística de esta epojé del discurso de ficción, visto ahora como mundos posibles ficcionales desde una semántica literaria cercana a Lubomir Dolezel (Garrido Domínguez, 1997, p. 64-92), está concentrada en la posibilidad de "juego" de los esquemas o estructuras mentales producidas por el esquematismo narrativo, que permiten el acto configurante de la trama en la escritura. En el acto de escritura de relatos de ficción el sujeto se comprende a sí mismo en tanto que reflexividad y es capaz de realizar juicios deliberativos sobre las posibilidades de ser que favorecen la actuación desde el marco de la vida buena.

La atestación del sí debe pasar de un nivel de reflexividad por el lenguaje, en la construcción del relato de ficción, a la del compromiso ontológico que se encarna en la estima de sí y el respeto de sí; esto es, pasar del decir a la actuación bajo el matiz de la vida buena. El relato por sí mismo no lleva al mundo de la realidad cruda y cotidiana, pero entre la actuación ética y la adscripción de una acción a un sujeto responsable media la descripción narrativa de las posibilidades de actuación que son también posibilidades de ser.

Los relatos de ficción son constructos textuales imaginativos, que muestran un posible estado de cosas en diversas formas variados y cuyo acceso es posible desde la realidad del mundo de la acción, no solo del lector, sino que primero del autor.

El proceso configurativo que va de la vida (con todo lo que implica cultural, simbólica, social e ideológicamente) al texto a través del lenguaje, es el proceso que nos interesa como juicio reflexivo vía el esquematismo narrativo en vista de que el mundo ficcional funciona como espacio de articulación imaginativa no solo de nuevas posibilidades para el mundo de 
la acción, sino de hermenéutica o interpretación del sí por mor de la estructura de las dialécticas que constituyen la hermenéutica del sí.

La fuerza modelizante del discurso narrativo está en este poder de lo imaginario, entendido como producto cultural y literario. Nuestros esquemas de representación de lo real son filtrados culturalmente por los esquemas mentales de primer orden que pueblan nuestro mundo cultural y por los de segundo orden que constituyen el universo de la literatura. Jerome Bruner ha relacionado estos esquemas como realidades mentales que permiten una construcción de una realidad subjentiva o un modelo de mundo ficcional que es, en definitiva, un modo de pensamiento (Bruner, 1996).

La ficción, en sentido general, activa nuestros esquemas mentales narrativos de modo tal que la configuración de la trama es un ejercicio reglado de creatividad producto de la imaginación. En tanto que mundo imaginado, el relato de ficción es el producto más representativo de la imaginación productora y permite que, el espacio figurativo construido por la elaboración de la trama, que es el paso de Mímesis I a Mímesis II, sea un camino abierto de posibilidades de construcción de realidades mentales que modelizan lo posible de la acción humana y construye semánticamente las opciones valorativas, estéticas y cognoscitivas del sujeto que escribe y que luego interviene en la realidad.

En definitiva, nuestra identidad personal, en tanto que identidad narrativa, es interpretación del sí construida ficticiamente (Mercau, 2011, p. 277) y atestiguada éticamente en la cohesión de una vida ética. ¿Qué es el "yo" a no ser una representación figurativa de nuestro ego históricamente situado? En otras palabras, el "yo" es un constructo ficcional, un objeto abstracto, una ficción teórica (Dennett, 1986), al cual accedemos por mediación del lenguaje, como una "figura" imaginada no solo producto de lo vivido, sino también como potencialidad de ser que se construye narrativamente.

\section{Referencias}

Bajtín, M. M. (1999). Estética de la creación verbal (10ma. ed.). (T. Bubnova, Trad.) México: Siglo XXI.

Bruner, J. (1996). Realidad mental y mundos posibles. Los actos de la imaginación que dan sentido a la experiencia. Barcelona: Gedisa.

Calvo Martínez, T. (1991). Del Símbolo al texto. En T. Calvo Martínez, \& R. Ávila Crespo, Paul Ricoeur: Los Caminos de la Interpretación (pp. 117-144). Barcelona: Anthropos.

Casarotti, E. (2012). El hombre capaz: claves antropológicas del pensamiento ético y político de P. Ricoeur. Filosofía Unisinos 13(2), 266-279.

Certeau, M. d. (1996). La Invención de lo Cotidiano. Artes de hacer. (Vol. 1). México: Universidad Iberoamericana.

Dennett, D. (1986). The self as a Center of Narrative Gravity. Philosophia, (15), 275-288.

Dolezel, L. (1997). Mímesis y mundos posibles. En A. Garrido Domínguez, Teorías de la ficción literaria (pp. 69-94). Madrid: Arco.

Ferraris, M. (2005). Historia de la Hermenéutica (2da. ed.). México: Siglo XXI.

Frege, G. (1998). Sentido y Referencia. En G. Frege, Ensayos de Semántica y Filosofía de la Lógica (pp. 84-112). Madrid: Tecnos.

Garrido Domínguez, A. (1997). La Teorías de la ficción literaria: los paradigmas. En A. Garrido Domínguez, Teorías de la ficción literaria (pp. 11-40). Madrid: Arco/Libros.

Grondin, J. (2008). ¿Qué es la hermenéutica? Barcelona: Herder.

Iser, W. (1997). La Ficcionalización: dimesión antropológica de las ficciones literarias. En A. Garrido D., Las Teorías de la Ficción Literaria (pp. 43-65). Madrid: Arco.

Kripke, S. (2005). El Nombrar y la necesidad. México: UNAM.

Mercau, H. H. (2011). Atestación y Atribución: hacia una ontología del Sí mismo como Otro en Paul Ricoeur. Problemata, 2, 274-290. 
Mora, J. E. (2009). Las variaciones imaginativas: tiempo, identidad e interacción. Acta fenomenológica latinoamericana. Volumen III (Actas del IV Coloquio Latinoamericano de Fenomenología), 705-722. Lima: Pontificia Universidad Católica del Perú.

Moratalla, A. D. (1991). Introducción al Pensamiento de Paul Ricoeur: Esperanza Militante y Creatividad reflexiva. Madrid: Instituto Enmanuel Monier.

Nájera, E. (2006). La Hermenéutica del sí de Paul Ricoeur entre Descartes y Nietzsche. Quaderns de filosofia i ciéncia, (36), 73-83.

Palmer, R. (2002). ¿Qué es la Hermenéutica? Madrid: Arcos/Libros.

Ricoeur, P. (1987a). Tiempo y Narración I. Configuración del tiempo en el relato histórico. (A. Neira, Trad.) Madrid: Cristiandad.

Ricoeur, P. (1987b). Tiempo y Narración II. La configuración del tiempo en el relato de ficción. (Vol. II). (A. Neira, Trad.) Madrid: Cristiandad.

Ricoeur, P. (1988). El discurso de la acción. Madrid: Cátedra.

Ricoeur, P. (1995). Teoría de la Interpretación. Discurso y Excedente de Sentido. México: Siglo XXI.

Ricoeur, P. (1996a). Sí mismo como Otro. México: Siglo XXI.

\section{Datos de filiación}

Roque Diómedes Santos Cueto. Doctorado en Filosofía por la Universidad del País Vasco, Profesor Investigador de la Universidad Autónoma de Santo Domingo (UASD). Líneas de investigación: Hermenéutica, Filosofía del lenguaje e imaginarios sociales.
Ricoeur, P. (1996b). Tiempo y Narración III. El tiempo narrado. México: Siglo XXI.

Ricoeur, P. (1997). Autobiografía Intelectual. Buenos Aires: Nueva Visión.

Ricoeur, P. (1999a). Para una teoría del discurso narrativo. En P. Ricoeur, Historia y Narratividad (pp. 83-155). Barcelona: Paidós.

Ricoeur, P. (1999b). Filosofía y Lenguaje. En P. Ricoeur, Historia y Narratividad (pp. 41-57). Barcelona: Paidós.

Ricoeur, P. (2001). La Metáfora Viva. Madrid: Cristiandad/Trotta.

Ricoeur, P. (2002). Del Texto a la Acción. Ensayos de Hermenéutica II. México: Fondo de Cultura Económica.

Ricoeur, P. (2003). El Conflicto de las Interpretaciones. Ensayos de Hermenéutica. México: Fondo de Cultura Económica.

Ricoeur, P. (2006). La vida: un relato en busca de narrador. Ágora, 25, 9-22.

Ricoeur, P. (2013). L'Homme comme sujet de la philosophie. En Paul Ricoeur, Antropologie Philosophique. Écrits et conférences 3 (pp. 305324). Paris: Seuil. 